\title{
Decreased Poly(ADP-Ribose) Polymerase 1 Expression Attenuates Glucose Oxidase-Induced Damage in Rat Cochlear Marginal Strial Cells
}

\author{
Yuanyuan Zhang ${ }^{1,2} \cdot$ Yang Yang $^{1} \cdot$ Zhen $\mathrm{Xie}^{1} \cdot$ Wenqi Zuo ${ }^{1} \cdot$ Hongyan Jiang ${ }^{1} \cdot$ \\ Xueyan Zhao ${ }^{1}$ - Yu Sun ${ }^{1}$ - Weijia Kong ${ }^{1}$
}

Received: 10 February 2015 / Accepted: 30 September 2015 / Published online: 2 November 2015

(C) The Author(s) 2015. This article is published with open access at Springerlink.com

\begin{abstract}
Oxidative damage to the inner ear is responsible for several types of sensorineural deafness. Cochlear stria marginal cells (MCs) are thought to be vulnerable to such oxidative stress. Activated poly(ADP-ribose) polymerase 1 (PARP1) has been implicated in several diseases, but the effect of PARP1 on MCs subjected to oxidative stress remains elusive. In this study, we established an in vitro cellular oxidative stress model using glucose oxidase (GO) and attempted to explore the role that PARP1 plays in the oxidative damage of MCs. In this study, PARP1 and poly-ADP-ribose (PAR) were highly expressed in GO-treated MCs, and this was accompanied by loss of MC viability, excessive generation of reactive oxygen species (ROS), collapse of mitochondria membrane potential $(\Delta \Psi \mathrm{m})$, and redistribution of the mitochondrial downstream pathway-related molecules Bax and cytochrome c, eventually causing $\mathrm{MC}$ death. These effects were almost completely counteracted by suppressing PARP1 expression with small interfering RNA (siRNA). We also found that caspase-3 activation was a downstream event of PARP activation and that apoptosis of MCs was suppressed, although not completely, by pretreatment with the pan-caspase inhibitor z-VAD-fmk. The suppression was less than that when PARP1 expression was inhibited. We conclude that GO treatment induces activation
\end{abstract}

Yuanyuan Zhang and Yang Yang contributed equally to this work.

Weijia Kong

entwjkong@hust.edu.cn

1 Department of Otorhinolaryngology, Union Hospital, Tongji Medical College, Huazhong University of Science and Technology, 1277 Jiefang Avenue, Wuhan 430022, China

2 Department of Otolaryngology — Head and Neck Surgery, Renmin Hospital, Wuhan University, 238 Jiefang Road, Wuhan 430060, China of PARP1, which causes MC damage via mitochondrial mediation. PARP1 plays a pivotal role in GO-induced MC death, at least in part, via the caspase- 3 cascade. Our study might provide a new cellular and molecular approach for the treatment of oxidative stress-related sensorineural deafness.

Keywords Poly(ADP-ribose) polymerase $1 \cdot$ Marginal cell · Hearing loss $\cdot$ Oxidative stress $\cdot$ Mitochondria $\cdot$ Apoptosis

\section{Introduction}

Oxidative damage to the inner ear is responsible for several types of sensorineural hearing loss, including presbycusis, hereditary deafness, noise deafness, and toxicity deafness. The damage causes reduced endocochlear potential (EP), inner ear reactive oxygen species (ROS) accumulation, and cell apoptosis, all of which eventually result in structural changes and functional impairment [1-3]. ROS derived from hydrogen peroxide $\left(\mathrm{H}_{2} \mathrm{O}_{2}\right)$, superoxide $\left(\mathrm{O}_{2}\right)$, and peroxynitrite (ONOO) are highly reactive and can lead to cell injury [4].

Glucose oxidase (GO) is a steady $\mathrm{H}_{2} \mathrm{O}_{2}$ generator; at a concentration of $10 \mathrm{mU} / \mathrm{ml}$, it can generate $\mathrm{H}_{2} \mathrm{O}_{2}$ continuously at a rate of $1.0-2.4 \mu \mathrm{M} / \mathrm{min}$ for up to $24 \mathrm{~h}$ in the presence of $5 \mathrm{mM}$ glucose [5]. Because glucose oxidase catalyzes the oxidation of D-glucose in vitro, high glucose concentrations generate ROS as a result of glucose auto-oxidation. Chang found that glucose oxidase and exogenous $\mathrm{H}_{2} \mathrm{O}_{2}$ have similar biological effects in that both induced apoptosis in HepG2 cells in vitro [5]. Based on these findings, GO was used to induce oxidative stress in our research.

It is well known that mitochondrial DNA (mtDNA) is a biologically important source of adenosine triphosphate (ATP) and that it is located in the vicinity of the respiratory chain, the main site where endogenous ROS are produced. 
Thus, elevated ROS can damage mitochondrial DNA, which may lead to severe consequences, including impairment of the respiratory chain and decreased ATP synthesis, collapse of mitochondrial membrane potential $(\Delta \Psi \mathrm{m})$, and even cell apoptosis [5, 6]. Because stria marginal cells (MCs) harbor much more mitochondria than other cells in the cochlea, they are particularly vulnerable to ROS attack [7]. Furthermore, MCs are believed to be extremely sensitive to oxidative damage caused by senility and noise $[8,9]$. However, the molecular mechanism of oxidative stress-induced apoptosis in marginal cells is not very clear. A better understanding of the cellular and molecular mechanisms associated with oxidative stressrelated strial marginal cell degeneration and declines in regenerative capacity is required to identify and explore potential interventional strategies for the prevention and treatment of oxidative stress-related hearing loss.

Poly(ADP-ribose) polymerase 1 (PARP1), a posttranslational modification enzyme found mainly in the nucleus but also in a few extranuclear sites of most eukaryotic cells, is called the genome guardian [10]. PARP could be activated when mtDNA is damaged [11], and it catalyzes the hydrolysis of NAD+ into nicotinamide and ADP-ribose, the latter of which is used to synthesize poly-ADP-ribose (PAR) [12], the activated form of PARP1 [13-16]. To prevent excessive NAD+ consumption and energy exhaustion, PARP is specifically disassembled into 24 - and $89-\mathrm{kDa}$ fragments by activated caspase-3, and the cells then enter the classic caspasedependent apoptosis process $[17,18]$. The fragments of PARP1 resulting from degradation by caspases are seen as an indicator of apoptosis [19, 20]. However, overactivated PARP1 could eventually lead to the exhaustion of cellular NAD and ATP and cell necrosis [21]. Thus, PARP1 is a key mediator of cell death.

Activated PARP1 has been implicated in several disease models [22-25]. However, the effect of PARP1 on marginal cells subjected to oxidative damage remains elusive. In this study, a PARP1 small interfering RNA (siRNA)-specific adenoviral vector was employed to examine the role that PARP1 plays in the GO-induced oxidative damage of MCs.

\section{Materials and Methods}

\section{Culture and Identification of Rat MCs}

MCs were primarily cultured following the procedures established by our laboratory [26]. Cytokeratin-18 (CK18), a previously established marker of MCs [27, 28], was detected by immunofluorescence. MCs were seeded onto coverslips precoated with poly-L-lysine (Sigma-Aldrich, St. Louis, MO, USA). After the cells fused to form a monolayer, the culture medium was discarded. Then, the samples were washed in cold phosphate-buffered saline (PBS) and fixed with $4 \%$ formalin for $15 \mathrm{~min}$ at room temperature. After three more washes with PBS, MCs were permeabilized in $0.3 \%$ Triton TM X-100 (Sigma-Aldrich, St. Louis, MO, USA) for $20 \mathrm{~min}$ and then washed three times with PBS. The cells were blocked for $10 \mathrm{~min}$ with a $5 \%$ bovine serum albumin (BSA) and then incubated overnight at $4{ }^{\circ} \mathrm{C}$ with a primary antibody against CK18 (1:50, Abcam, Cambridge, MA, USA). The following day, the cells were stained with anti-rabbit $\operatorname{IgG}(1: 100)$ for $30 \mathrm{~min}$ at room temperature and then washed three times with PBS. The cells were washed and stained with 4',6-diamidino2-phenylindole (DAPI, Sigma-Aldrich, St. Louis, MO, USA) at room temperature for $3 \mathrm{~min}$ to identify the nuclei. Afterward, the slides were mounted and visualized under a fluorescence electron microscope.

\section{GO Exposure}

We measured cellular activity by detecting formazan transformed from WST-8 in active cells using a cell counting kit (CCK-8/WST-8, Dojindo Laboratories, Kumamoto, Japan). Briefly, cells were resuspended once the MCs fused to form a monolayer. The MCs were then seeded into 96-well plates, allowed to adhere to the plate, and then treated with different concentrations of GO for $24 \mathrm{~h}$. Each concentration was tested in triplicate. Then, $20 \mu \mathrm{l}$ of a CCK- 8 test solution was added to each well, with $0 \mathrm{mU} / \mathrm{ml} \mathrm{GO}$ serving as the control group and wells without cells serving as blanks. The absorbance was determined at $450 \mathrm{~nm}$ after incubation for $1.5 \mathrm{~h}$ at $37^{\circ} \mathrm{C}$. In the CCK- 8 assay, methyl thiazolyl tetrazolium WST- 8 is cleaved to soluble formazan by active cells, and the corresponding optical density (OD) value is indicative of the cellular activities of MCs. The activity of cells $\times \%=\left(\mathrm{OD}_{\text {experimental }}{ }^{-}\right.$ $\left.\mathrm{OD}_{\text {medium blank }}\right) /\left(\mathrm{OD}_{\text {control }}-\mathrm{OD}_{\text {medium blank }}\right) \times 100 \%$.

\section{Transfection of MCs with Adenovirus}

Once MCs fused to form a monolayer, they were cultured with EpiCM-animal medium containing the Ad-PARP1-RNAi recombinant virus (GeneChem, Shanghai, China) for $4 \mathrm{~h}$. Afterward, the MCs were treated with $20 \mathrm{mU} / \mathrm{ml} \mathrm{GO}$ for $24 \mathrm{~h}$ and then harvested. As a mock-infected group, MCs were also infected with non-specific siRNA. Infection efficiency was assessed in terms of PARP1 expression as measured by reverse transcription-polymerase chain reaction (RT-PCR) and western blotting (described below).

\section{Grouping}

MCs were randomly divided into six groups: (1) control (untreated MCs), (2) GO (MCs were treated with $20 \mathrm{mU} / \mathrm{ml} \mathrm{GO}$ for $24 \mathrm{~h}$ ), (3) GO+ Ad-PARP1-RNAi (after infection with AdPARP1-RNAi, MCs were treated with $20 \mathrm{mU} / \mathrm{ml} \mathrm{GO}$ for $24 \mathrm{~h}$ ), (4) GO+mock (after infection with Ad-mock-RNAi, 
MCs were treated with $20 \mathrm{mU} / \mathrm{ml} \mathrm{GO}$ for $24 \mathrm{~h}$ ), (5) GO+zVAD-fmk (after treatment with $50 \mu \mathrm{mol} / 1 \mathrm{z}$-VAD-fmk for $30 \mathrm{~min}, \mathrm{MCs}$ were treated with $20 \mathrm{mU} / \mathrm{ml} \mathrm{GO}$ for $24 \mathrm{~h}$ ), and (6) z-VAD-fmk (MCs treated with $50 \mu \mathrm{mol} / \mathrm{l}$ z-VAD-fmk for $30 \mathrm{~min})$.

\section{Evaluation of Apoptosis by Flow Cytometry and DAPI Nuclear Staining}

Annexin V-FITC/propidium iodide (PI) double labeling was used to evaluate the rate of MC apoptosis. Briefly, after each treatment, cells were rinsed twice with cold PBS and incubated with trypsin until $80 \%$ of the cells were detached. Cell suspensions were collected and centrifuged at $1000 \mathrm{rpm}$ for $5 \mathrm{~min}$. The supernatant was discarded, and cold PBS was used to wash the pellets two times. The cells $\left(1 \times 10^{5}\right)$ were resuspended in $100 \mu \mathrm{l}$ of $1 \times$ binding buffer containing $5 \mu \mathrm{l}$ annexin $\mathrm{V}$-FITC and $10 \mu \mathrm{PI}$, incubated for $15 \mathrm{~min}$ at room temperature in the dark, and then (BD Biosciences, Carlsbad, CA) analyzed by flow cytometry. After DAPI nuclear staining (as described below), the cells were monitored under a fluorescence microscope for nuclear change.

\section{Detection of Intracellular ROS Content and Distribution by Flow Cytometry and Laser Confocal Microscopy}

The intracellular ROS level was detected using DCFHDA (Beyotime, Shanghai, China), an oxidation-sensitive fluorescence probe. Cells were seeded into six-well plates $\left(1 \times 10^{5}\right.$ cells/well) and treated in terms of grouping (Fig. 4) for the indicated amount of time. They were then cultured with DCFH-DA $(10 \mu \mathrm{M})$ for $30 \mathrm{~min}$ at room temperature and examined by flow cytometry. The distribution of ROS was detected by coculturing cells with MitoTracker Red CMXRos (a mitochondria-selective dye; Invitrogen, Carlsbad, CA, USA) and DCFH-DA and then visualizing them by fluorescence microscopy.

Determination of $\Delta \Psi \mathrm{m}$ was performed using a multifunctional microplate reader and fluorescence microscopy. Changes in $\Delta \Psi \mathrm{m}$ were detected using the Mito-ID membrane potential cytotoxicity kit (ENZO Life Sciences, NY, USA) according to the manufacturer's instructions. Briefly, after treatment, the cells in each group were loaded with MitoTracker at $37^{\circ} \mathrm{C}$ for $30 \mathrm{~min}$. The fluorescence signal $(\mathrm{Ex}=485 \mathrm{~nm} / \mathrm{Em}=$ $590 \mathrm{~nm}$ ) of $\Delta \Psi \mathrm{m}$ was read on a plate reader (BioTek ${ }^{\circledR}$ Synergy 2 Multi-Mode microplate reader, USA) and visualized under a fluorescence microscope.

\section{Immunofluorescence and Confocal Microscopy}

We detected the distribution of PARP1, cytochrome c, and Bax in the MCs by immunofluorescence and confocal microscopy (LSCM, Nikon, Tokyo, Japan). MCs were first seeded onto polylysine-treated coverslips. After the cells fused to form a monolayer, they were treated with $300 \mathrm{nM}$ MitoTracker and then incubated at $37{ }^{\circ} \mathrm{C}$ for $45 \mathrm{~min}$. Afterward, the cells were stained with primary antibodies overnight at $4{ }^{\circ} \mathrm{C}$ (anti-PARP1 1:50, anti-Bax 1:25, Santa Cruz, CA, USA; anti-CytC 1:100, Invitrogen, Carlsbad, CA, USA). After the specimens were incubated with the corresponding secondary fluorescent antibodies for $30 \mathrm{~min}$, the nuclei were labeled with DAPI for $3 \mathrm{~min}$ at room temperature. The MCs were then mounted and observed under an LSCM. The laser beam was set at $488 \mathrm{~nm}$ for the FITC-conjugated antibody, at $555 \mathrm{~nm}$ for MitoTracker, and at $405 \mathrm{~nm}$ for DAPI. Images were acquired simultaneously in the green, red, and blue channels. Images were imported into the Corel Draw X5 software package (Corel, Canada), and the images of representative cells from each well were recorded.

\section{Measurement of Cytochrome $\mathrm{C}$ and Bax in the Mitochondrial/Cytosol}

A mitochondria/cytosol isolation kit was used to separate the mitochondria and cytosol of MCs according to the manufacturer's protocol (BioVision, San Francisco, USA). After treatment with GO $(20 \mu \mathrm{M} / \mathrm{ml}, 24 \mathrm{~h})$ or pretreatment with Adr for $24 \mathrm{~h}$, cells $\left(5.0 \times 10^{7}\right)$ were collected and suspended in $1 \mathrm{ml}$ of isolation buffer containing protease inhibitors and lysed on ice for $10 \mathrm{~min}$. After mechanical homogenization with a Dunce grinder, a mixture containing unbroken cells, debris, and nuclei was separated by centrifugation at $800 \times \mathrm{g}$ for $10 \mathrm{~min}$ at $4{ }^{\circ} \mathrm{C}$. The supernatants were centrifuged at $10,000 \times \mathrm{g}$ for $30 \mathrm{~min}$ at $4{ }^{\circ} \mathrm{C}$ to obtain the cytosolic fraction (supernatant). The pellets were resuspended in $100 \mu \mathrm{l}$ Mitochondrial Extraction Buffer Mix containing DTT and protease inhibitors, vortexed for $10 \mathrm{~s}$, and then saved as the mitochondrial fraction. The mitochondria and cytosol were used for detection of cytochrome c and Bax by western blotting.

\section{Determination of Caspase-3 Activity}

Because activated caspase- 3 plays a critical role in the final classical pathway in caspase-dependent apoptosis, the activity of caspase- 3 was determined using a chemical self-illumination technique that employs Ac-DEVD-AFC (ENZO Life Sciences, USA), a specific fluorogenic substrate for caspase-3. The activity of caspase-3 was determined on a multifunctional microplate reader equipped with a 400-nm excitation filter and a 505-nm emission filter. All assays were carried out in triplicate, and the results were expressed as fold change relative to the control group. 


\section{Western Blotting}

MCs seeded in six-well plates $\left(3.0 \times 10^{5} /\right.$ well $)$ were pretreated with a virus for $48 \mathrm{~h}$ and then treated with $\mathrm{GO}(20 \mathrm{mU} / \mathrm{ml}, 24 \mathrm{~h})$. The cells were harvested and homogenized in RIPA lysis buffer (Beyotime, Shanghai, China) containing $1 \mathrm{mM}$ phenylmethylsulfonyl fluoride. The homogenate was centrifuged and the supernatant was collected. Protein concentration was determined using a BCA kit. Cell lysates were subjected to $12 \%$ SDS-polyacrylamide gel electrophoresis (PAGE), followed by protein transfer to a PVDF membrane and incubation with anti-PARP1, anti-Bax (Santa Cruz, CA, USA), anti-PAR (ENZO Life Sciences, USA), anti-CytC (Invitrogen, CA, USA), anti-cleaved caspase-3 (Abcam, Cambridge, UK), and $\beta$-actin (Cell Signaling Technology, MA, USA) antibodies. Immunoblots were probed with horseradish peroxidase-conjugated secondary antibodies and visualized using an enhanced chemiluminescent reagent (Millipore, MA, USA). The band intensity was determined by densitometry using a ChemiDoc XRS (BioRad, USA) and normalized to $\beta$-actin. The change in protein levels was expressed relative to the control.

\section{RNA Isolation and Real-Time PCR}

Following treatment, messenger ribonucleic acid (mRNA) was isolated from rat MCs using Trizol ${ }^{\circledR}$ reagent (Invitrogen, Carlsbad, CA, USA) according to the manufacturer's instructions. RNA concentration was measured in terms of the $\mathrm{OD}_{260} / 280$ ratio. mRNA was reverse transcribed into complementary deoxyribonucleic acid (cDNA) using a high-capacity cDNA reverse transcription kit (Applied Biosystems, CA, USA). Realtime PCR was performed in a final volume of $10 \mu$ using Power SYBR Green PCR Master Mix reagents (Applied Biosystems, CA, USA) and run on an ABI Prism 7300 Real-Time PCR System (Applied Biosystems, CA, USA). Each sample was analyzed in triplicate, and glyceraldehyde-3-phosphate dehydrogenase (GAPDH) was used as an internal control. The primer pairs used for PARP1 and GAPDH were as follows: PARP1 forward, 5'-GAGTGGGCACAGTT-ATCGGC-3'; PARP1 reverse, 5'CCAGGC ATTTCCAGTCTTCTCT-3'; GAPDH forward, 5'TT CAACGGCACAGT CAAGG-3'; PARP1 reverse, 5'CTCAGCACCAGCATCACC-3'. The amplification conditions were as follows: $95^{\circ} \mathrm{C}$ for $30 \mathrm{~s}$, followed by 40 cycles of denaturation at $95{ }^{\circ} \mathrm{C}$ for $30 \mathrm{~s}$, annealing at $60{ }^{\circ} \mathrm{C}$ for $60 \mathrm{~s}$, and extension at $95{ }^{\circ} \mathrm{C}$ for $5 \mathrm{~s}$. Changes in mRNA levels were corrected against GAPDH using the 2- $\Delta \Delta \mathrm{CT}$ method.

\section{Statistical Analysis}

The results were expressed as the mean \pm SEM of the three measurements. The statistical analyses were conducted using the SPSS 19.0 software package (IBM, USA). One-way ANOVA and a two-tailed independent-sample $t$ test were used for the evaluation of the differences between the treatment and control groups. Differences with a $P \leq 0.05$ were considered to be significant. The western blotting images were quantitatively assessed by employing ImageJ software (NIH, USA). The chi-square test was used to assess the variation in apoptosis rates between groups, and the corrected $P$ value $\left(P^{\prime}=P /[k(k-\right.$ 1)/2]t1) was employed for multiple comparisons.

\section{Results}

\section{Primary Culture and Identification of MCs}

Figure 1 shows that the MCs present a pleomorphic growth pattern, with a clear boundary. MCs were closely connected and grew into a monolayer, assuming a "cobblestone-like" appearance. Fluorescent signals indicative of CK18 (a biomarker of the epithelium) were strong in the cultured cells.

\section{Expression of PARP1 in MCs}

As shown in Fig. 2a, PARP1 was mainly expressed in nuclei, and a few signals overlapped with the fluorescence of mitochondria. RT-PCR and western blotting showed that after MCs were infected with the Ad-PARP1-RNAi recombinant adenoviruses, PARP1 expression was dramatically decreased at both the mRNA and protein levels when compared to the control and mock-infected groups (Fig. 2b, c).

\section{Effect of GO Treatment on MC Viability and PARP1 Activity}

Figure 3a shows that treatment with a lower concentration of GO slightly increased the viability of MCs, although the increase was not statistically significant. In contrast, GO concentrations over $10 \mathrm{mU} / \mathrm{ml}$ induced a statistically significant loss of viability in a concentration-dependent manner. We deduced that the concentration of GO required to induce oxidative damage in MCs was $20 \mathrm{mU} / \mathrm{ml}$ and that this results in a considerable reduction in viability compared to the $0 \mathrm{mU} / \mathrm{ml}$ treatment group $(P<0.05)$.

Western blotting revealed that, after treatment with $20 \mathrm{mU} /$ $\mathrm{ml} \mathrm{GO}$ for $24 \mathrm{~h}$, PAR and PARP1 cleavage proteins ( $85 \mathrm{kDa})$ were significantly upregulated compared to the control group (Fig. 3b) $(P<0.01)$. In contrast, infection with the Ad-PARP1RNAi virus before GO treatment downregulated the expression $(P<0.01)$.

\section{ROS Generation in MCs}

The ROS accumulation and distribution in MCs were observed by flow cytometry and fluorescence microscopy, respectively. The results showed that exposure of MCs to 


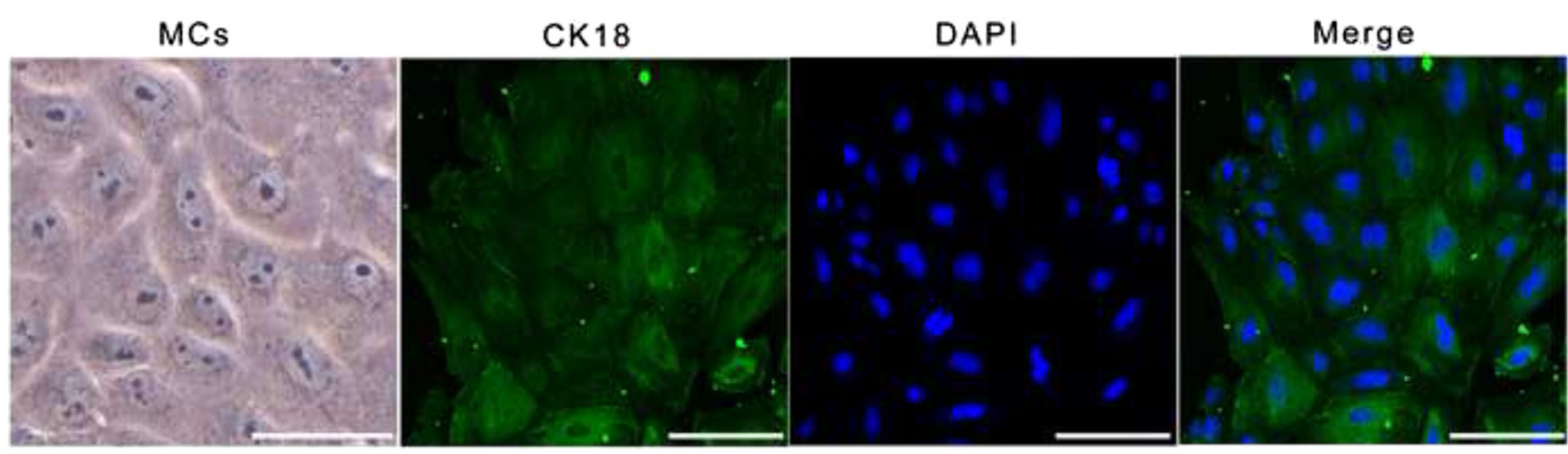

Fig. 1 The morphology and identification of MCs. The cultured primary cells with clear boundaries present with a "cobblestone-like" appearance. Immunofluorescence of CK18 ( green) expressed in the cytoplasm; nuclei are stained blue

$20 \mathrm{mU} / \mathrm{ml} \mathrm{GO}$ for $24 \mathrm{~h}$ increased ROS generation approximately fourfold compared to the control group (Fig. 4a, b; $P<0.01)$. The ROS production of the GO+Ad-PARP1-RNAi group was significantly reduced compared to the GO group $(P<0.01)$. However, the $\mathrm{GO}+$ mock group did not exhibit any change in ROS generation when compared to the GO group $(P>0.05)$. Figure $4 \mathrm{c}$ shows that most of the DCFH-DA signals (green florescence) overlapped with the MitoTracker signals (red florescence). These findings suggested that the mitochondria were primarily responsible for the generation of ROS, rendering MCs sensitive to oxidative damage and that inhibition of PARP1 could counteract the GO-induced increase of intracellular ROS.

\section{Death from Exposure to GO}

Figure 5a, b shows that exposure of MCs to $20 \mathrm{mU} / \mathrm{ml} \mathrm{GO}$ for $24 \mathrm{~h}$ resulted in a significantly increased rate of apoptosis compared to the control group $(P<0.01)$. However, MCs in the $\mathrm{GO}+$ mock group did not exhibit any change in the rate of apoptosis compared to the GO group $(P>0.05)$.

DAPI staining revealed that, after exposure to $\mathrm{GO}$ for $24 \mathrm{~h}$, the nuclei of the MCs were condensed and fragmented, suggesting that the cells were apoptotic. Fluorescence microscopy showed similar results. In the cells in the GO+Ad-PARP1RNAi group, the characteristic apoptotic changes in the nuclei were much less pronounced (Fig. 5c). The findings were consistent with the results of FACS.

\section{PARP1-Modulated MC Death}

To assess mitochondrial damage in MCs after exposure to $\mathrm{GO}$, we measured $\Delta \Psi \mathrm{m}$ in MCs by fluorescence detection using a microplate reader and under a microscope. Concomitant with the increase in mitochondrial ROS levels, MC $\Delta \Psi \mathrm{m}$ sharply declined in the $\mathrm{GO}$ and $\mathrm{GO}+$ mock groups compared to the control group (Fig. 6a; $P<0.01)$, and the $\Delta \Psi \mathrm{m}$ increased significantly in the $\mathrm{GO}+\mathrm{Ad}-\mathrm{PARP} 1-\mathrm{RNAi}$ group $(P<0.01)$. Under a fluorescence microscope, $\mathrm{MCs}$ in the $\mathrm{GO}$ and $\mathrm{GO}+$ mock groups presented green fluorescence, which is indicative of apoptotic cells. On the contrary, $\mathrm{MCs}$ in the $\mathrm{GO}+\mathrm{Ad}-$ PARP1-RNAi and control groups displayed a large amount of orange fluorescence, which is indicative of healthy cells (Fig. 6b). Data obtained from the fluorescence microplate reader showed similar results (Fig. 6a). These findings suggested the PARP1 could modulate the GO-induced apoptosis of MCs via mitochondria, but that inhibition of PARP expression could protect mitochondria from dysfunction.

\section{Relocation of Bax and Cytochrome C}

Western blotting and immunofluorescence were performed to investigate the possible mechanism of MC death after $\Delta \Psi \mathrm{m}$ loss and to elucidate the role of PARP1 in the process. Western blotting showed that the expression of Bax in the mitochondria was increased in the GO group, and, as a result, Bax protein levels were reduced in the cytosol compared to control cells. Pretransfection with Ad-PARP1-RNAi could significantly counteract this change (Fig. $7 \mathrm{a} ; P<0.01$ ). There was no difference in protein relocation between the $\mathrm{GO}+$ mock and GO groups $(P>0.05)$. The relocation pattern of cytochrome $\mathrm{c}$ in MCs was opposite to that of Bax (Fig. 7b).

Consistent with the results of western blotting, fluorescence microscopy showed that Bax (green fluorescence) was located in the cytosol and separated from the MitoTracker (red fluorescence) and that cytochrome c fully overlapped with mitochondria in control cells, presenting orange fluorescence (Fig. 7c, d). Conversely, Bax gradually migrated into mitochondria after GO treatment and partially overlapped with red MitoTracker, indicating they colocalized in the mitochondria (Fig. 7c). Moreover, cytochrome c was scattered in the cytosol (Fig. 7d). However, preinfection with Ad-PARP1-RNAi could clearly counteract these changes. In the $\mathrm{GO}+$ mock group, no such changes were observed. 


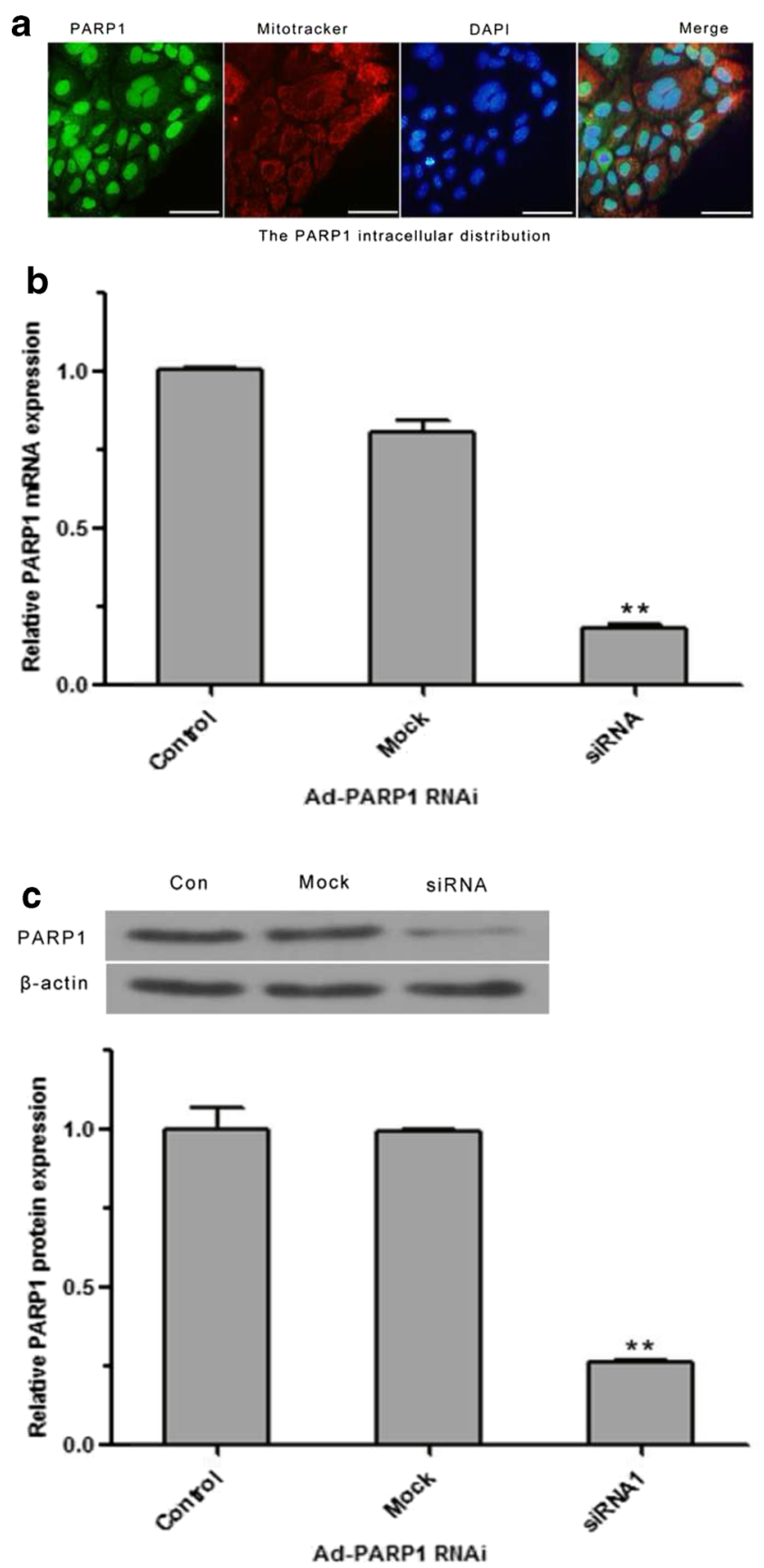

Fig. 2 The expression of PARP1 in MCs. a PARP1 produces green fluorescence which was mainly found in the nuclei. A few extranuclear PARP1 signals overlapped with the red fluorescence marking the mitochondria. b, c The changes in PARP1 mRNA and protein expression after cells were infected with Ad-PARP1-RNAi recombinant virus or non-specific siRNA. The data are presented as the mean $\pm \mathrm{SEM}$ of three separate experiments. $* * P<0.01$ vs. the control group. Scale bar $=$ $50 \mu \mathrm{m}$

\section{Effect of z-VAD-fmk on the Death of MCs}

Activation of the classic caspase-dependent pathway is the core mechanism that leads to apoptotic cell death. Release of cytochrome $\mathrm{c}$ from the mitochondria to the cytosol is essential
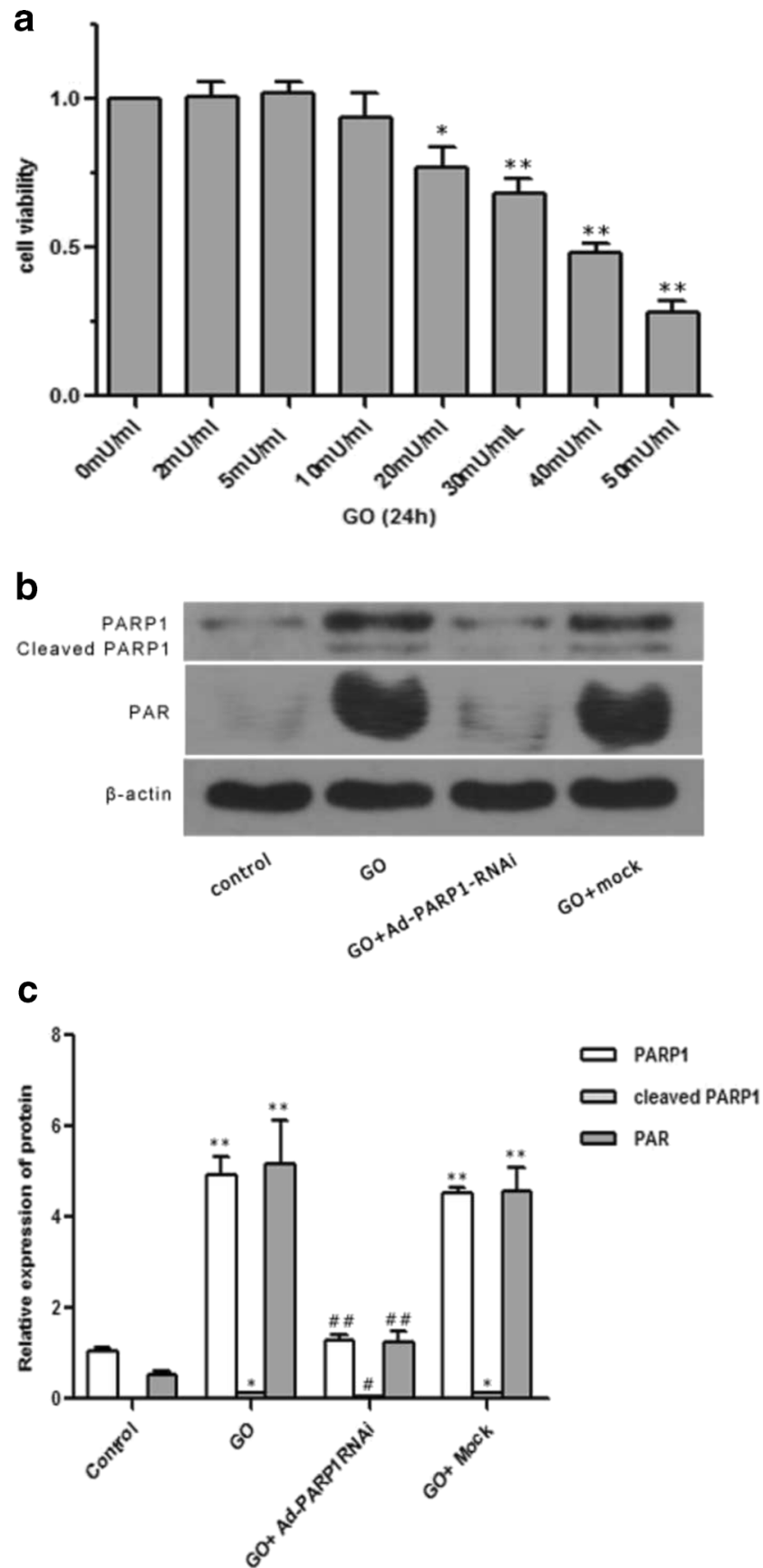

Fig. 3 GO treatment induces PARP1 activation. The optimal concentration of GO treatment as determined by the CCK8 test. The control group was treated with $0 \mathrm{mU} / \mathrm{ml} \mathrm{GO}$. The cellular viability of groups that were exposed to over $10 \mathrm{mU} / \mathrm{ml} \mathrm{GO}$ was all less than that of the control group, indicating that the growth of the MCs was suppressed when the GO concentration was greater than $10 \mathrm{mU} / \mathrm{ml}$ and that the appropriate concentration of GO was $20 \mathrm{mU} / \mathrm{ml}$. b, c The relative protein levels of PARP1 and PAR in each group. The levels of PAR and PARP1 cleavage proteins $(85 \mathrm{kDa})$ increased significantly in the GO group compared to the control group $(P<0.01)$, indicating that PARP1 was activated in MCs exposed to $20 \mathrm{mU} / \mathrm{ml}$ GO for $24 \mathrm{~h}$. All of the $Y$ axis values of the western blot assays represent the percentage of protein expression relative to $\beta$-actin. The data are presented as the mean \pm SEM of three separate experiments. $* P<0.05$ vs. the control group, $* * P<0.01$ vs. the control group, \#\#P<0.01 vs. the GO group 
Fig. 4 Detection of intracellular ROS levels. a, b The ROS accumulation (green fluorescent DCF) in MCs was measured using a fluorescence spectrometer ( $\lambda$ ex $490 \mathrm{~nm}, \lambda$ em $515 \mathrm{~nm}$ ) and by flow cytometry and

fluorescence microscopy. c The distribution of intracellular ROS was detected by co-culturing the cells with MitoTracker (red) and DCFH-DA (green) and then observing them under a fluorescence microscope. $* * P<0.01$ vs. the control group, $\# \# P<0.01$ vs. the GO group. Data are expressed as the mean + SEM $(n=3)$. Scale bar $=50 \mu \mathrm{m}$
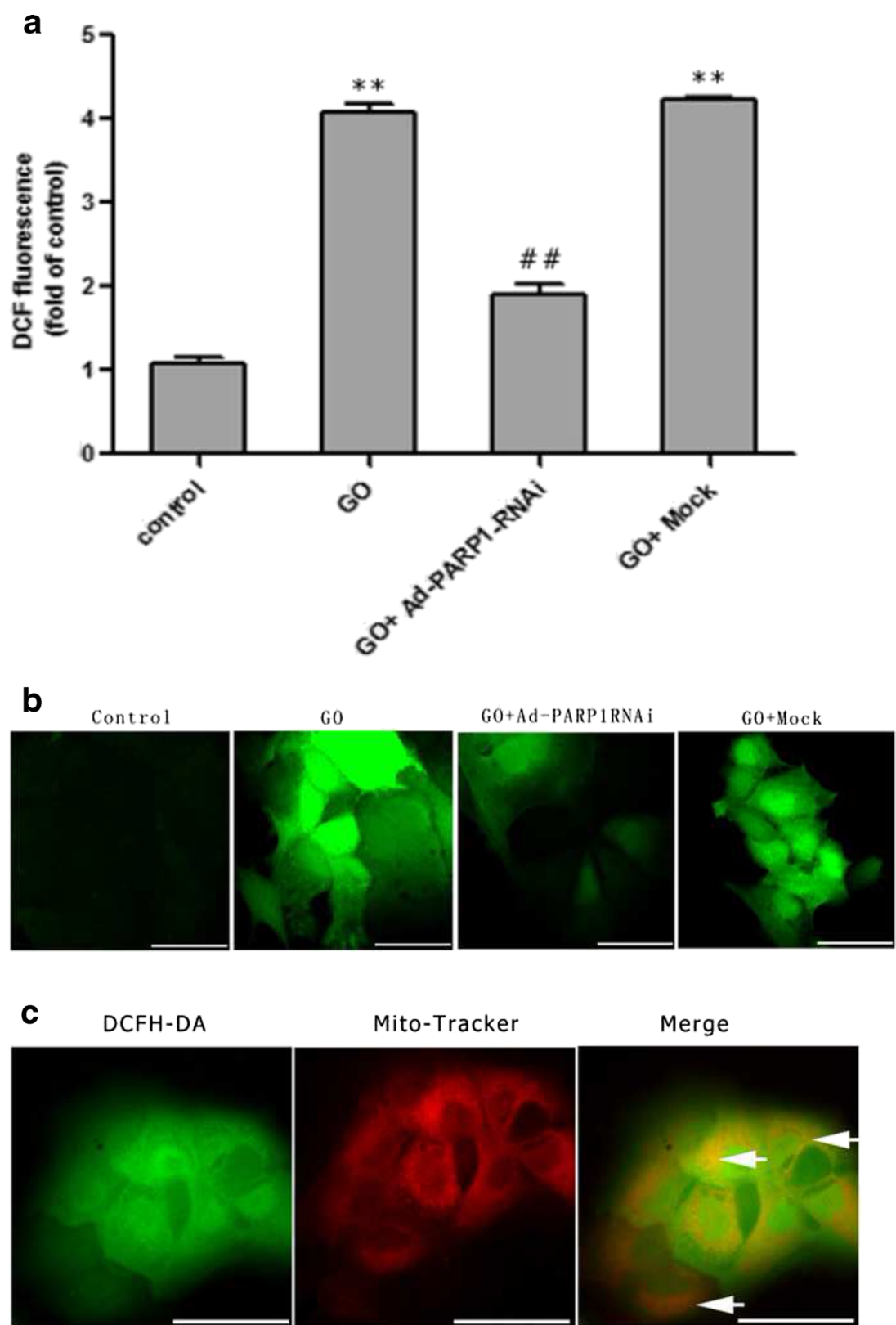

Mito-Tracker

Merge
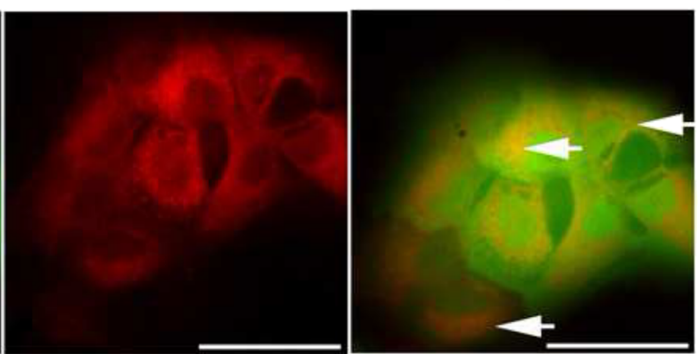

The ROS intracellular distribution for the induction of apoptosis [29]. The finding that inhibition of PARP1 could prevent GO-induced cell death prompted us to examine the correlation between caspase- 3 activation and activated PARP1.

Figure $8 \mathrm{a}$ shows that the amount of cleaved caspase3 was significantly higher in the GO group than in the control group $(P<0.01)$ and that caspase-3 cleavage was significantly lower in the GO+Ad-PARP1-RNAi group $(P<0.01)$ compared to the GO group. This change in the pattern of cleaved caspase- 3 was similar to that observed with PAR (Fig. 3b) which is an indicator of the activity of PARP1.
We then pretreated MCs with $50 \mu \mathrm{mol} / \mathrm{l}$ z-VAD-fmk for 30 min before GO treatment and measured caspase- 3 activity using Ac-DEVD-AFC, a caspase-3-specific substrate. Figure $8 \mathrm{~b}$ shows that caspase- 3 activity sharply increased in the GO group compared to the control group $(P<0.01)$, while in both the GO+Ad-PARP1-RNAi and GO+z-VAD-fmk groups, caspase-3 activity apparently decreased compared to the GO group $(P<0.01)$. There were no differences in caspase- 3 activity between the $\mathrm{GO}+$ mock and GO groups $(P>0.05)$. These findings indicated that caspase- 3 was activated by GO treatment and that its activity could be abolished by z-VAD-fmk or by inhibiting PARP1. 
Fig. 5 Detection of cell apoptosis. a, b The rate of apoptosis was determined by flow cytometry after annexin V-APC/ PI staining. The lower left quadrants contain the viable cells (AV-/PI-), the lower right quadrants contain the early apoptotic cells (AV+/PI-), the upper right quadrants contain the late apoptotic cells (AV+/PI+), and the upper left quadrants contain the necrotic cells $(\mathrm{AV}-/$ $\mathrm{PI}+)$. c The morphology of MC nuclei was visualized by fluorescence microscopy after DAPI staining. Untreated MCs remained morphologically normal. Typical apoptotic changes such as nuclear condensation (white arrows) and nuclear fragmentation (red arrows) were observed in the GO group and in the $\mathrm{GO}+$ mock group. $* * P<0.01$ vs. the control group, $\# \# P<0.01$ vs. the GO group. Data are expressed as the mean $+\operatorname{SEM}(n=3)$.

Scale bar $=50 \mu \mathrm{m}$
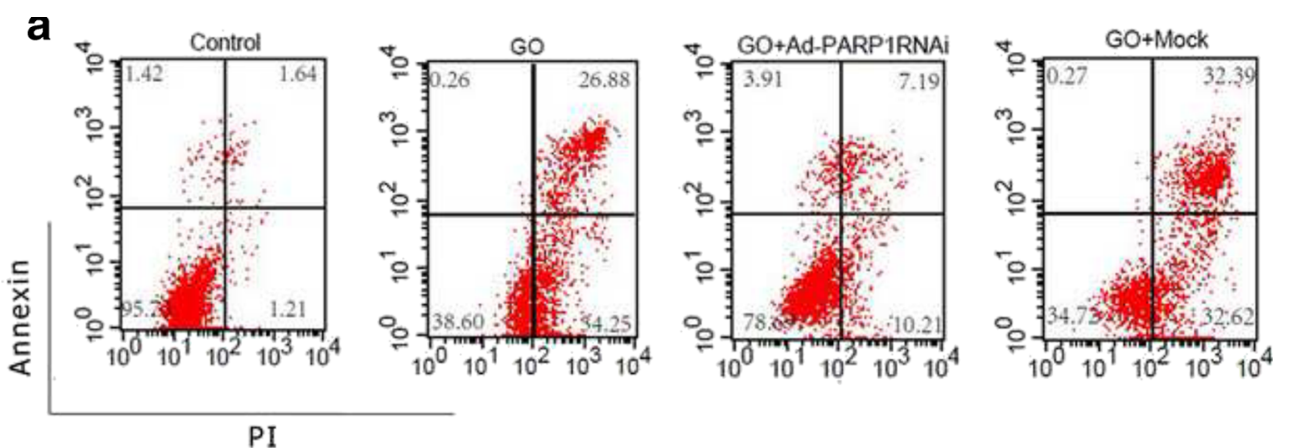

PI
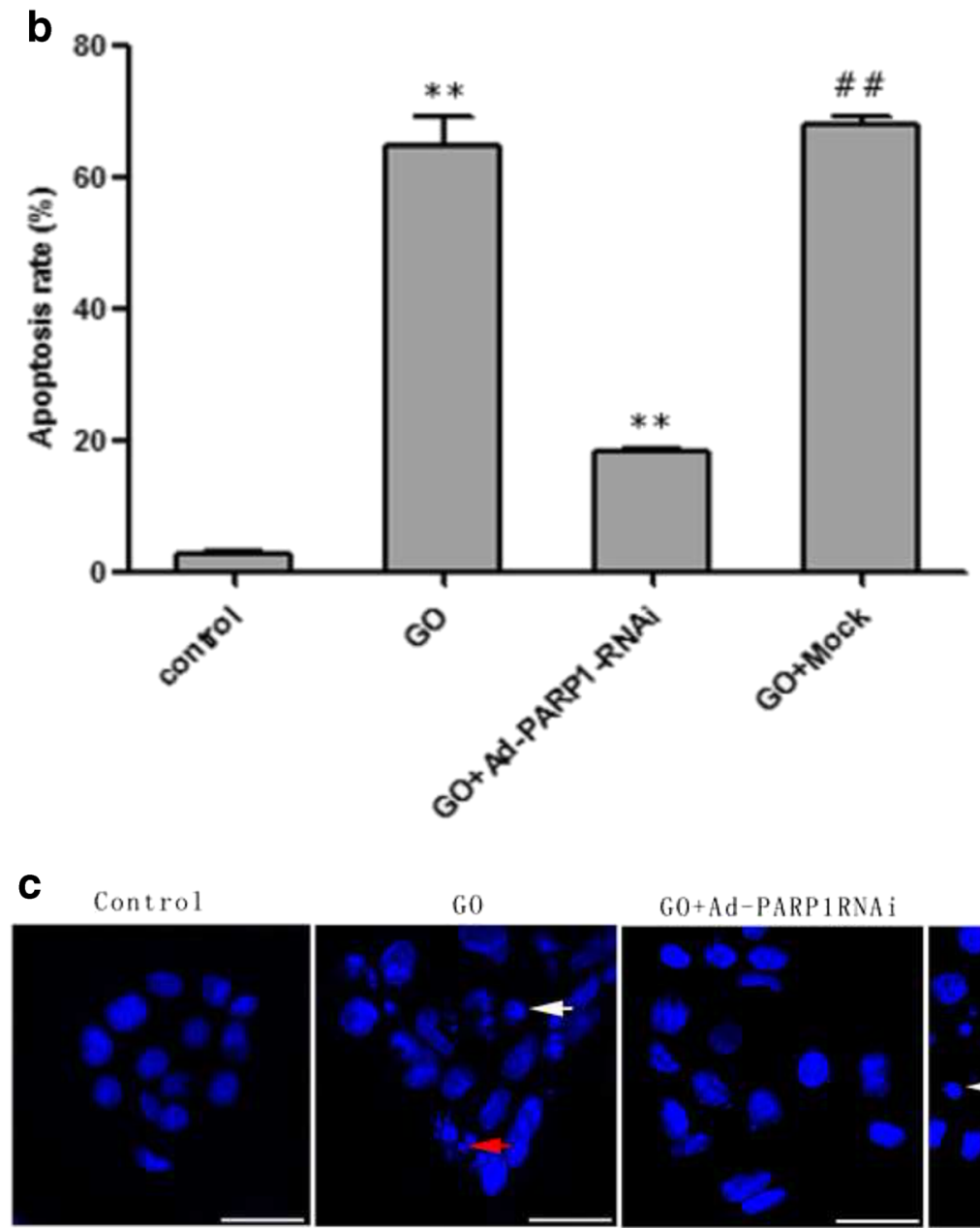

G0

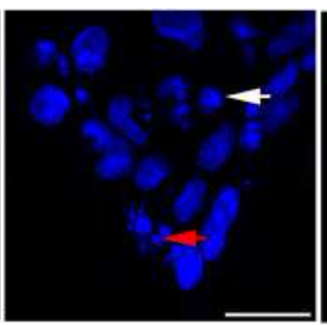

G0+Ad-PARP1RNAi
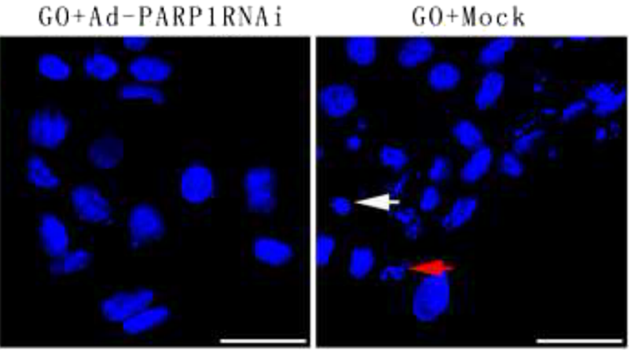

Western blotting showed that the levels of both cleaved caspase- 3 and cleaved PARP1 were reduced in the GO+zVAD-fmk group compared to the GO group (Fig. 8c; $P<0.05)$ but that full-length PARP1 was not inhibited.

Flow cytometry revealed that the apoptosis of MCs was decreased to some extent in the GO+z-VAD-fmk group compared to the GO group (Fig. $8 \mathrm{~d} ; P<0.05$ ). However, the rate of $\mathrm{MC}$ apoptosis in the GO+z-VAD-fmk group (34.77\%) was higher than that $(17.4 \%)$ in the GO+Ad-PARP1-RNAi group (Fig. 5a).

\section{Discussion}

Maintenance of endocochlear potential is essential for normal hearing and depends primarily on the pumping mechanism of the marginal cells of the cochlear lateral wall. A wide array of pathological and physiological changes induced by aging, stress, ischemia, noise, and ototoxic agents can cause irreversible damage to marginal cells, leading to excessive generation of ROS and eventually to auditory impairment. PARP1, a molecular sensor of DNA damage [30], is activated when 
Fig. 6 PARP1 RNAi ameliorates the loss of mitochondrial membrane potential. Changes in $\Delta \Psi \mathrm{m}$ between groups of MCs were detected using a

multifunctional microplate reader (a) and a fluorescence microscope (b). a The fluorescence signals $(E x=485 \mathrm{~nm} / E m=590 \mathrm{~nm})$ of $\Delta \Psi \mathrm{m}$ in MCs were monitored on a multifunctional microplate reader after they were loaded with MitoTracker. b Upon analysis by fluorescence microscopy, the healthy cells present orange florescence (white arrows), and the cells with a decreased $\Delta \Psi \mathrm{m}$ emitted only green fluorescence (red arrows). Data are expressed as the mean $+\operatorname{SEM}(n=3)$.

$* * P<0.01$ vs. the control group, $\# \# P<0.01$ vs. the GO group. Scale bar $=50 \mu \mathrm{m}$
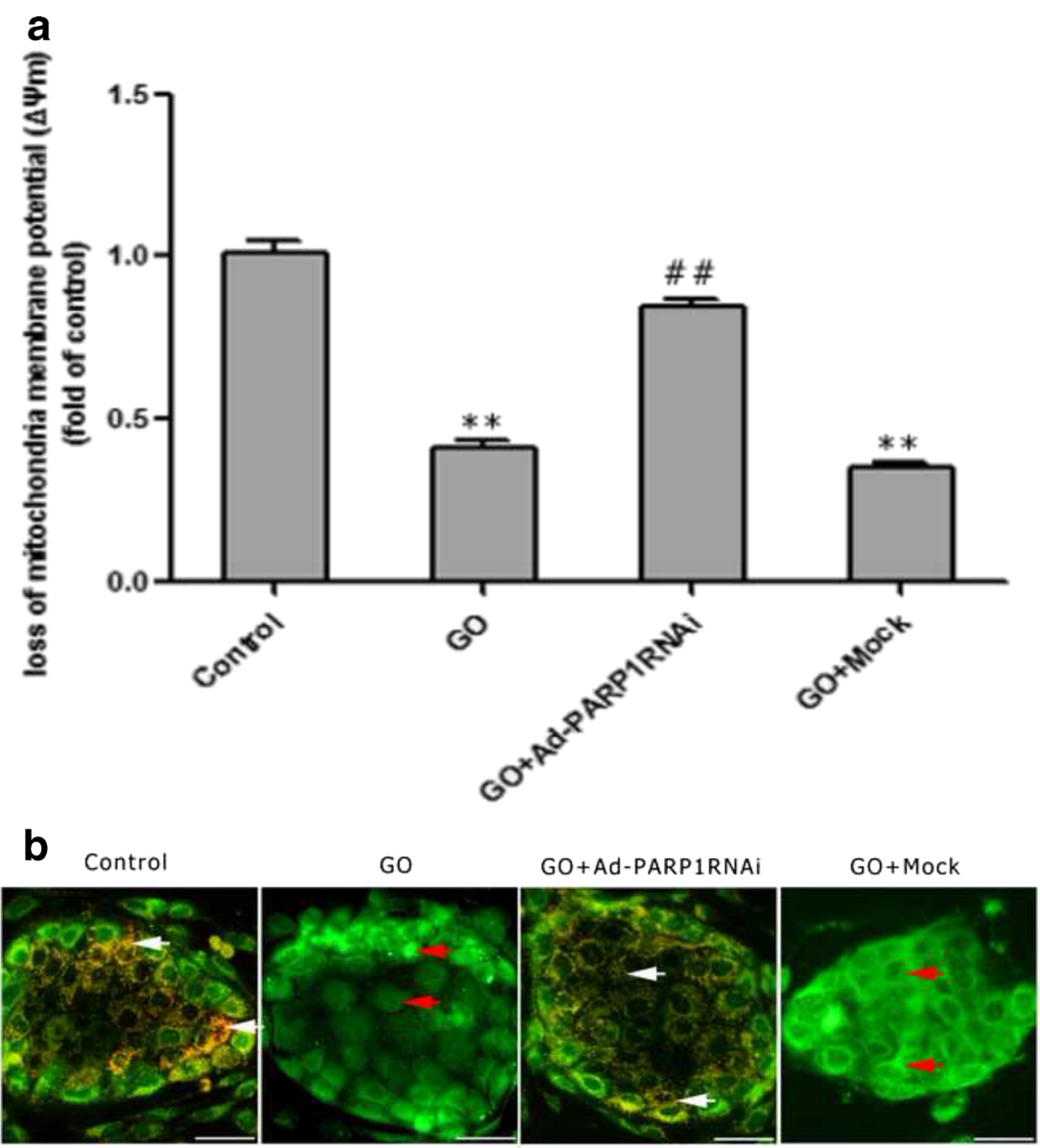

DNA is damaged and is thought to play a role in a variety of diseases, such as diabetes [6, 22], arthritis [23], Parkinson's and Alzheimer's diseases, cerebral ischemia, traumatic brain injury [24], and some malignancies such as ovarian carcinoma [25]. Regarding the inner ear, most studies about the effect of PARP1 have been conducted in the outer hair cells and a few have been carried out in spiral ganglion neurons. In fact, little research effort has been directed at the role of PARP1 in MCs. However, at present, the role that PARP1 plays in different inner cells remains controversial. Shi [31] demonstrated that PARP1 was activated in some marginal cells and in some vessels of the spiral ligaments and that activated PARP1 could stimulate the expression of $\mathrm{P}$-selectin and platelet-endothelial cell-adhesion molecule-1 in the vessels of the spiral ligament after exposure to loud noise, thereby triggering inflammatory events. Although Jiang [32] found that PARP1 was decreased in a mouse model of progressive kanamycin-induced hair cell loss, they failed to detect the 89-kDa PARP1 fragment derived from caspase and markers of classic apoptotic pathways (cytochrome c, caspase-9, caspase-3, JNK, and TUNEL). Thus, the role of PARP1 in the oxidative damage of MCs remains poorly understood. In this study, we established an in vitro cellular oxidative stress model using GO and attempted to explore the role that PARP1 plays in the oxidative damage of MCs.

In this study, the treatment of MCs with $20 \mu \mathrm{M} / \mathrm{ml} \mathrm{GO}$ induced an apparent loss of cell viability. Meanwhile, PARP1 expression and activity were significantly enhanced in the GO-treated group compared to the control group (Fig. 3; $P<0.01$ ), as was ROS generation and MC apoptosis (Figs. 4 and $5 ; P<0.01)$. DAPI staining also revealed typical apoptotic changes, such as nuclear shrinkage and fragmentation. PARP1 activity was counteracted by preinfection with Ad-PARP1RNAi, and this was accompanied by the downregulation of ROS generation and MC apoptosis. These results suggest that ROS generation and MC death could be regulated by activated PARP1 and raise the question as to how PARP1 regulates the death of MCs.

Excessive ROS generation is generally followed by three changes that lead to cell apoptosis: depolarization of the inner mitochondrial membrane, release of Bcl-2 family proteins from the mitochondria, and the opening of the permeability transition pore (PTP) [33-35]. Of these, loss of mitochondrial membrane potential $(\Delta \Psi \mathrm{m})$ is believed to be a crucial factor in the apoptotic pathway. In most cells, excessive ROS are produced by the mitochondria, which are easy targets of 

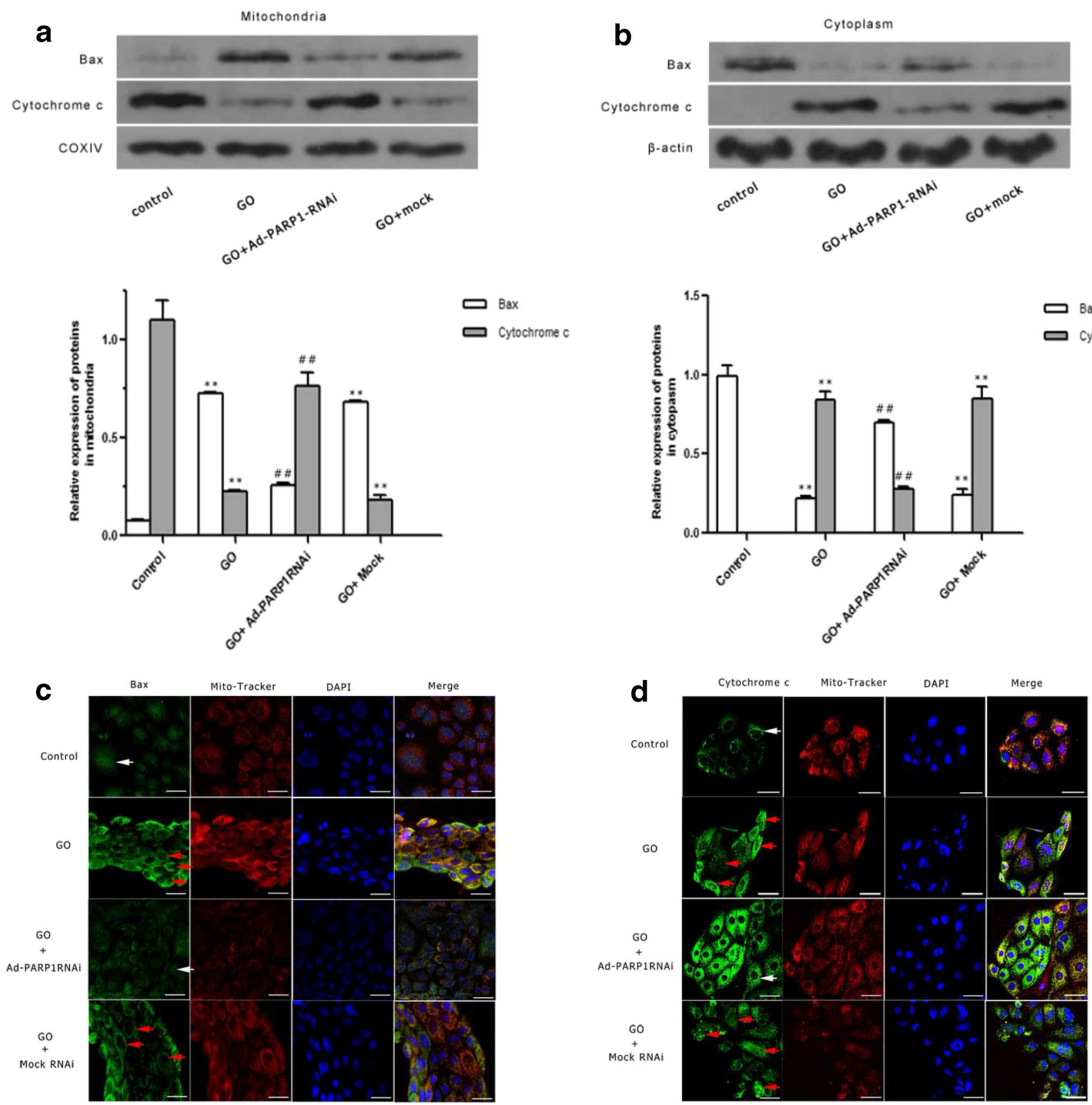

Fig. 7 Relocation of Bax and CytC. a, b Western blot analysis showed the relative expression of Bax and cytochrome $\mathrm{c}$ in the mitochondria and cytoplasm, respectively. c, d The immunofluorescence of Bax, cytochrome c, and MitoTracker and their subcellular distribution during the GO-induced apoptosis of MCs were detected simultaneously by confocal microscopy. Green fluorescence represents Bax and

ROS attack [36]. This study showed that the intense green DCFH-DA signals overlapped with the red MitoTracker signals in GO-treated MCs, suggesting that GO could induce excessive ROS generation and that mitochondria are responsible for the local generation of most ROS. Additionally, LSCM and western blotting showed that, in GO-treated MCs, the decrease in $\Delta \Psi \mathrm{m}$ was accompanied by the recruitment of Bax from the cytosol to the mitochondria and that this

cytochrome c and red fluorescence is indicative of MitoTracker. White arrows show the distribution of Bax and cytochrome $\mathrm{c}$ in the control and GO+Ad-PARP1RNAi group cells (c, d). Red arrows indicate the redistribution of Bax and cytochrome $\mathrm{c}$ in the $\mathrm{GO}$ and $\mathrm{GO}+$ mock group cells. The results are given as the mean of three separate experiments. Scale bar $=50 \mu \mathrm{m}$

was followed by relocation of cytochrome $\mathrm{c}$ from the mitochondria to the cytosol. Furthermore, decreased PARP1 protein levels inhibited the relocation of a series of deathassociated proteins and prevented the death of MCs. Our study suggested that strong PARP activation might transmit a death signal to the mitochondria, thereby causing depolarization of the mitochondrial transmembrane potential and the relocation of Bax, a member of the anti-apoptotic protein family, leading 


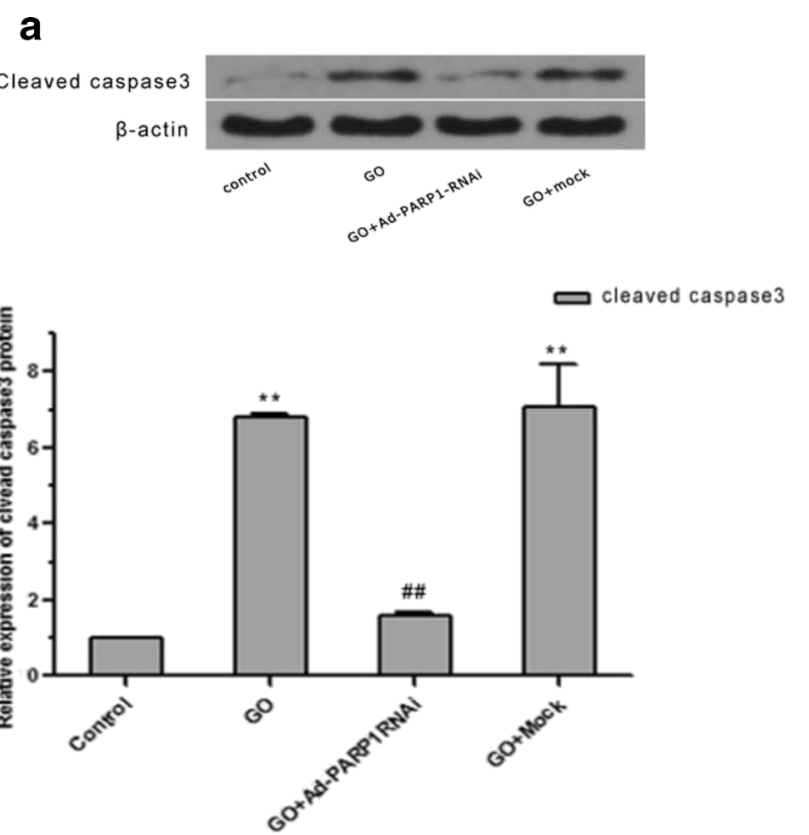

\section{C}

Cleaved caspase 3
PARP1
Cleaved PARP1

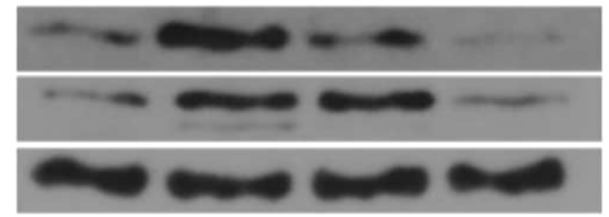

$c_{0} \times r^{400} \quad 6^{\circ}$

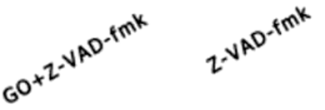

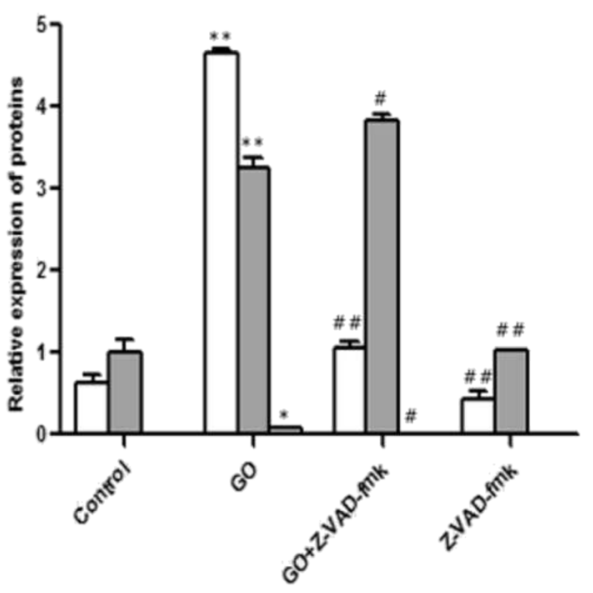

d

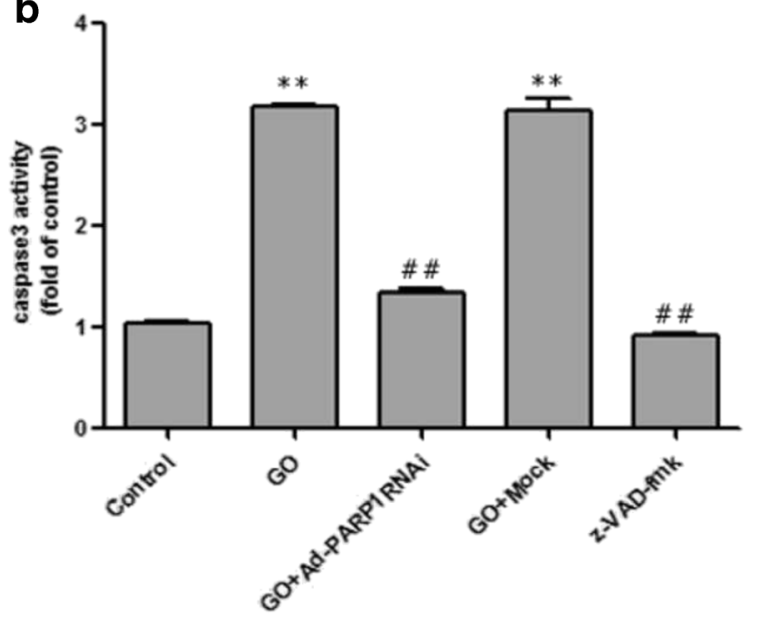

Fig. 8 PARP1-induced MC death is partly caspase-dependent. a Western blot analysis showed the relative expression of cleaved caspase- 3 in each group. $\mathbf{b}$ The activity of caspase- 3 following treatment of each group was measured using a multifunctional microplate reader. $\mathbf{c}$ The change in the amounts of cleaved caspase- 3 and PARP1 expression in MCs was

to the opening of high-permeability pores and the release of cytochrome $\mathrm{c}$ from the mitochondria to the cytoplasm. Our results demonstrated that PARP1 activation could trigger and regulate $\mathrm{MC}$ death via a mitochondria-mediated pathway.
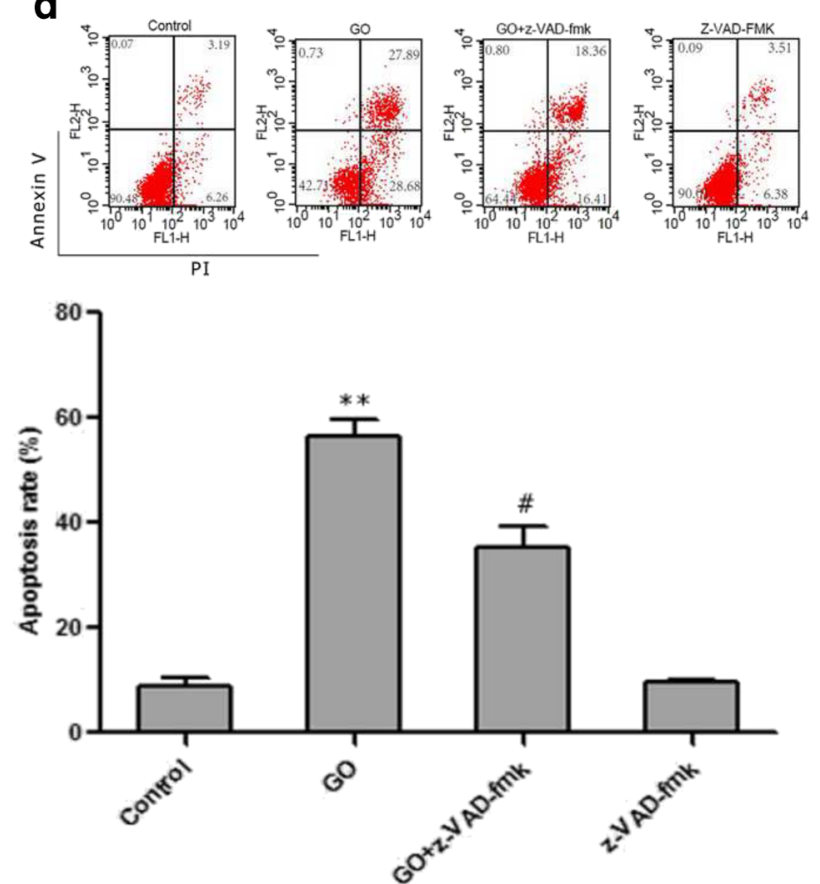

detected by western blotting. $\mathbf{d}$ Differences in the rate of MC apoptosis were determined by flow cytometry after annexin V-APC/PI staining. Data are expressed as the mean $+\operatorname{SEM}(n=3) . * * P<0.01$ vs. the control group, $\# P<0.05$ vs. the $\mathrm{GO}$ group, $\# \# P<0.01$ vs. the $\mathrm{GO}$ group

Our findings raise the question as to how PARP1 siRNA downregulates ROS generation in MCs and protects mitochondria from oxidative damage. Previous reports showed that oxidant-induced functional changes in the mitochondria 
are related to PARP1 activation rather than to the direct effect of the oxidant on the mitochondria [37]. A number of studies have shown that the poly-ADP-ribosylation of nuclear proteins is involved in DNA repair or transcriptional regulation $[7,38]$. Less is known about how PARP(s) work on mitochondrial proteins. Many studies have demonstrated that, in mitochondria, poly-ADP-ribosylation occurred [39-41], which may be involved in mitochondrial function. Lai [42] believed that mitochondrial PARP1 could ADP-ribosylate many mitochondrial proteins (VDAC1, mitofilin, cytochrome c reductase core protein, COX subunit Va, etc.) at the transcriptional level, thereby resulting in the dysfunction of the respiratory chain. The dysfunction of the respiratory chain could lead to the generation of excessive ROS, which cannot be removed in time, eventually causing functional impairment of the mitochondria [43]. We found that some PARP1 was localized to the mitochondria (Fig. 2a), and this led us to believe that mitochondrial PARP1 might be involved in the regulation of mitochondria-mediated MC death induced by GO.

Activation of the caspase cascade is intimately correlated to mitochondrial oxidative dysfunction. Once cytochrome $\mathrm{c}$ releases from damaged mitochondria and enters the cytosol, the caspase cascade will be activated. Cytochrome c plays a primary role in the formation of the apoptosome complex by activating the binding of procaspase-9 to Apaf-1 [44]. The complex then activates caspase- 3 , leading to cleavage of PARP1 and caspase-dependent apoptosis [20, 45]. To further clarify the presence of the classic apoptotic cascade in GOinduced MC apoptosis and the relationship between PARP1 and caspase-3, we detected the cleavage of caspase-3, an indicator of caspase- 3 activity. The results indicated that PARP1 siRNA effectively prevented caspase-3 activation in MCs compared to MCs treated with GO alone (Fig. 8a; $P<0.01$ ), suggesting that caspase activation was a downstream event of PARP activation.

To further understand whether the caspase-dependent pathway was solely responsible for PARP-dependent apoptosis in MCs, we pretreated the cells with the pan-caspase inhibitor zVAD-fmk before GO exposure. We found that the cleavage and activity of caspase-3 were much lower in the z-VAD-fmkpretreated group than in the GO-treated group. In addition, the z-VAD-fmk-pretreated cells showed a decrease in cleaved PARP1, a product of full-length PARP1 cleavage. The study illustrated that z-VAD-fmk effectively inhibited caspase-3 activity and decreased the PARP1 cleavage fragments as opposed to full-length PARP1 in MCs. In agreement with these results, flow cytometry showed that the apoptosis of MCs was suppressed, although not completely, by z-VAD-fmk pretreatment (Fig. $7 \mathrm{c} ; P<0.05)$ and that the suppression was less than when PARP1 expression was inhibited (Fig. 5a). We conclude that the caspase-associated apoptotic pathway is not the sole pathway implicated in PARP1-dependent MC death induced by GO. There may be other mechanisms in addition to the typical caspase-dependent pathway that function in MCs. This notion is different from the conclusion drawn from a previous study suggesting that z-VAD-fmk could completely block the $\mathrm{NGF} / \mathrm{p} 75 \mathrm{ngfr} / \mathrm{ceramide}$-induced apoptosis of epithelial cells and neurons in otocysts and the cochleovestibular ganglia [46]. A more recent study found that z-VAD-fmk significantly reduced the number of annexin V-positive renal cancer cells and that this apoptosis was considered to be caspasedependent [47]. However, Jiang et al. failed to detect the markers of classic apoptotic pathways (cytochrome c, caspase-9, caspase-3, JNK, and TUNEL) in a mouse model of progressive kanamycin-induced hair cell loss [32].

Based on our results, we concluded the following: (1) Treatment of MCs with GO could mimic oxidative damage to MCs and that GO could considerably suppress MC activity and induce massive ROS generation and apoptosis in MCs. (2) Mitochondria are responsible for the generation of most local ROS in MCs and are vulnerable to ROS attack induced by GO. (3) GO treatment induces the activation of PARP1, leading to a decreased $\Delta \Psi \mathrm{m}$ via mitochondrial mediation, and facilitates the relocation of the molecules in the downstream pathway. Mitochondrial PAR might take part in the regulation of mitochondria-mediated MC death. (4) PARP1 plays a pivotal role in GO-induced MC death that is, at least in part, via the caspase-3 pathway. (5) In addition to the caspasedependent pathway, there might be other apoptotic pathways involved in PARP1-dependent GO-induced MC death.

Compliance with Ethical Standards All procedures involving animals were performed in strict accordance with the Guide for the Care and Use of Laboratory Animals of the National Institutes of Health (NIH), and the protocols were approved by the Committee on the Ethics of Animal Experiments of Huazhong University of Science and Technology, Wuhan, China.

Funding This study was funded by the Major State Basic Research Development Program of China (973 Program) (No. 2011CB504504), the National Nature Science Foundation of China (No. 81200745, No. 81000409 ), and the Wuhan Science \& Technology Plan Projects (No. 2015060101010042).

Conflict of Interest The authors declare that they have no competing interests.

Open Access This article is distributed under the terms of the Creative Commons Attribution 4.0 International License (http:// creativecommons.org/licenses/by/4.0/), which permits unrestricted use, distribution, and reproduction in any medium, provided you give appropriate credit to the original author(s) and the source, provide a link to the Creative Commons license, and indicate if changes were made.

Open Access This article is distributed under the terms of the Creative Commons Attribution 4.0 International License (http:// creativecommons.org/licenses/by/4.0/), which permits unrestricted use, distribution, and reproduction in any medium, provided you give appropriate credit to the original author(s) and the source, provide a link to the Creative Commons license, and indicate if changes were made. 


\section{References}

1. Sastre J, Pallardo FV, Vina J (2003) The role of mitochondrial oxidative stress in aging. Free Radic Biol Med 35(1):1-8

2. Takumida M, Anniko M, Popa R (1998) Possible involvement of free radicals in lipopolysaccharide-induced labyrinthitis in the guinea pig: a morphological and functional investigation. ORL J Otorhinolaryngol Relat Spec 60(5):246-253

3. Huang T, Cheng AG, Stupak H, Liu W, Kim A, Staecker H, Lefebvre PP, Malgrange B et al (2000) Oxidative stress-induced apoptosis of cochlear sensory cells: otoprotective strategies. Int $\mathrm{j}$ Dev Neurosci 18(2-3):259-270

4. Prindull G (1995) Apoptosis in the embryo and tumorigenesis. Eur J Cancer 31A(1):116-123

5. Lin CJ, Ho HY, Cheng ML, You TH, Yu JS, Chiu DT (2010) Impaired dephosphorylation renders G6PD-knockdown HepG2 cells more susceptible to $\mathrm{H}(2) \mathrm{O}(2)$-induced apoptosis. Free Radic Biol Med 49(3):361-373

6. Ma Y, Ogino T, Kawabata T, Li J, Eguchi K, Okada S (1999) Cupric nitrilotriacetate-induced apoptosis in HL-60 cells association with lipid peroxidation, release of cytochrome $\mathrm{C}$ from mitochondria, and activation of caspase-3. Free Radic Biol Med 27(1-2):227-233

7. Silva JP, Larsson NG (2002) Manipulation of mitochondrial DNA gene expression in the mouse. Biochim Biophys Acta 1555(1-3): 106-110

8. Spicer SS, Schulte BA (2005) Pathologic changes of presbycusis begin in secondary processes and spread to primary processes of strial marginal cells. Hear Res 205(1-2):225-240

9. Keiko H, Christopher MD, Jodi RK, Ransohoff R (2005) Mononuclear phagocytes migrate into the murine cochlea after acoustictrauma. J Comp Neurol 489(2):180-194

10. Hotz HR, Biebinger S, Flaspohler J, Clayton C (1998) PARP gene expression: control at many levels. Mol Biochem Parasit 91(1): 131-143

11. Putt KS, Hergenrother PJ (2004) An enzymatic assay for poly(ADP-ribose) polymerase-1 (PARP-1) via the chemical quantitation of $\mathrm{NAD}(+)$ : application to the high-throughput screening of small molecules as potential inhibitors. Anal Biochem 326(1):78-86

12. Woodhouse BC, Dianov GL (2008) Poly ADP-ribose polymerase-1: an international molecule of mystery. DNA Repair 7(7): 1077-1086

13. Ba X, Gupta S, Davidson M, Garg NJ (2010) Trypanosoma cruzi induces the reactive oxygen species-PARP-1-RelA pathway for upregulation of cytokine expression in cardiomyocytes. J Biol Chem 285(15):11596-11606

14. Martin SS, Perez-Polo JR, Noppens KM, Grafe MR (2005) Biphasic changes in the levels of poly(ADP-ribose) polymerase-1 and caspase 3 in the immature brain following hypoxia-ischemia. Int J Dev Neurosci 23(8):673-686

15. Muñoz-Gámez JAR-VJ, Quiles-Pérez R, Aguilar-Quesada R, Martín-Oliva D, de Murcia G, Menissier de Murcia J, Almendros A, Ruiz de Almodóvar M et al (2009) PARP-1 is involved in autophagy induced by DNA damage. Autophagy 5(1):61-74

16. Huang Q, Wu YT, Tan HL, Ong CN, Shen HM (2009) A novel function of poly(ADP-ribose) polymerase-1 in modulation of autophagy and necrosis under oxidative stress. Cell Death Differ 16(2):264-277

17. Diamantopoulos PT, Sofotasiou M, Papadopoulou V, Polonyfi K, Iliakis T, Viniou NA (2014) PARP1-driven apoptosis in chronic lymphocytic leukemia. BioMed Res Int 2014:106713

18. Mathieu J, Flexor M, Lanotte M, Besancon F (2008) A PARP-1/ JNK1 cascade participates in the synergistic apoptotic effect of
TNFalpha and all-trans retinoic acid in APL cells. Oncogene 27(24):3361-3370

19. Moon H, Baek D, Lee B, Prasad DT, Lee SY, Cho MJ, Lim CO, Choi MS et al (2002) Soybean ascorbate peroxidase suppresses Bax-induced apoptosis in yeast by inhibiting oxygen radical generation. Biochem Biophys Res Commun 290(1):457-462

20. Ari F, Ulukaya E, Sarimahmut M, Yilmaz VT (2013) Palladium(II) saccharinate complexes with bis(2-pyridylmethyl)amine induce cell death by apoptosis in human breast cancer cells in vitro. Bioorg Med Chem 21(11):3016-3021

21. Szabo C, Dawson VL (1998) Role of poly(ADP-ribose) synthetase in inflammation and ischaemia-reperfusion. Trends Pharmacol Sci 19(7):287-298

22. Masutani M, Suzuki H, Kamada N, Watanabe M, Ueda O, Nozaki T, Jishage K, Watanabe T et al (1999) Poly(ADP-ribose) polymerase gene disruption conferred mice resistant to streptozotocininduced diabetes. Proc Natl Acad Sci U S A 96(5):2301-2304

23. Pacher P, Szabo C (2008) Role of the peroxynitrite-poly(ADP-ribose) polymerase pathway in human disease. Am J Pathol 173(1):2-13

24. Tentori L, Portarena I, Graziani G (2002) Potential clinical applications of poly(ADP-ribose) polymerase (PARP) inhibitors. Pharmacol Res 45(2):73-85

25. Sakogawa K, Aoki Y, Misumi K, Hamai Y, Emi M, Hihara J, Shi L, Kono K et al (2013) Involvement of homologous recombination in the synergism between cisplatin and poly (ADP-ribose) polymerase inhibition. Cancer Sci 104(12):1593-1599

26. Zhao XY, Sun JL, Hu YJ, Yang Y, Zhang WJ, Hu Y, Li J, Sun Yet al (2013) The effect of overexpression of PGC-1alpha on the mtDNA4834 common deletion in a rat cochlear marginal cell senescence model. Hear Res 296:13-24

27. Thoren FB, Romero AI, Hellstrand K (2006) Oxygen radicals induce poly(ADP-ribose) polymerase-dependent cell death in cytotoxic lymphocytes. J Immunol 176(12):7301-7307

28. Karbowski M, Kurono C, Wozniak M, Ostrowski M, Teranishi M, Nishizawa Y, Usukura J, Soji T et al (1999) Free radical-induced megamitochondria formation and apoptosis. Free Radic Biol Med 26(3-4):396-409

29. Marzo I1, Brenner C, Zamzami N, Jürgensmeier JM, Susin SA, Vieira HL, PrévostMC, Xie Z, Matsuyama S, Reed JC, G. K (1998) Bax and adenine nucleotide translocator cooperate in themitochondria control of apoptosis. Science 281(5385):20272031

30. Welsby IHD, Leo O (2012) Complex roles of members of the ADPribosyl transferase superfamily in immune defences. Biochem Pharmacol 84(1):11-20

31. Shi X, Nuttall AL (2007) Expression of adhesion molecular proteins in the cochlear lateral wall of normal and PARP-1 mutant mice. Hear Res 224(1-2):1-14

32. Jiang H, Sha SH, Forge A, Schacht J (2006) Caspase-independent pathways of hair cell death induced by kanamycin in vivo. Cell Death Differ 13(1):20-30

33. Rarey KE, Patterson K (1989) Establishment of inner ear epithelial cell culture: isolation, growth and characterization. Hear Res 38(3): 277-287

34. Du L, Zhang X, Han YY, Burke NA, Kochanek PM, Watkins SC, Graham SH, Carcillo JA et al (2003) Intra-mitochondrial poly(ADPribosylation) contributes to $\mathrm{NAD}+$ depletion and cell death induced by oxidative stress. J Biol Chem 278(20):18426-18433

35. Xiong S, Mu T, Wang G, Jiang X (2014) Mitochondria-mediated apoptosis in mammals. Protein Cell 5(10):737-749

36. Yang J, Xiao YL, He XR, Qiu GF, Hu XM (2010) Aesculetininduced apoptosis through a ROS-mediated mitochondrial dysfunction pathway in human cervical cancer cells. J Asian Nat Prod Res 12(3):185-193 
37. Virag L, Salzman AL, Szabo C (1998) Poly(ADP-ribose) synthetase activation mediates mitochondrial injury during oxidantinduced cell death. J Immunol 161(7):3753-3759

38. Ha HC, Hester LD, Snyder SH (2002) Poly(ADP-ribose) polymerase-1 dependence of stress-induced transcription factors and associated gene expression in glia. Proc Natl Acad Sci U S A 99(5):3270-3275

39. Burzio LO, Saez L, Cornejo R (1981) Poly (ADP-ribose) synthetase activity in rat testis mitochondria. Biochem Biophys Res Commun 103(1):369-375

40. Melichar I, Gitter AH (1991) Primary culture of vital marginal cells from cochlear explants of the stria vascularis. Eur Arch Otorhinolaryngol 248(6):358-365

41. Scovassi AI (2004) Mitochondrial poly(ADP-ribosylation): from old data to new perspectives. FASEB J 18(13):1487-1488

42. Lai Y, Chen Y, Watkins SC, Nathaniel PD, Guo F, Kochanek PM, Jenkins LW, Szabo C et al (2008) Identification of poly-ADPribosylated mitochondrial proteins after traumatic brain injury. $\mathrm{J}$ Neurochem 104(6):1700-1711
43. Kang D, Hamasaki N (2005) Alterations of mitochondrial DNA in common diseases and disease states: aging, neurodegeneration, heart failure, diabetes, and cancer. Curr Med Chem 12(4):429-441

44. Zou H, Li YC, Liu HS, Wang XD (1999) An APAF-1 center dot cytochrome $\mathrm{c}$ multimeric complex is a functional apoptosome that activates procaspase-9. J Biol Chem 274(17):11549-11556

45. Michels J, Vitale I, Senovilla L, Enot DP, Garcia P, Lissa D, Olaussen KA, Brenner C et al (2013) Synergistic interaction between cisplatin and PARP inhibitors in non-small cell lung cancer. Cell Cycle 12(6):877-883

46. Yu HY, Kim SO, Jin CY, Kim GY, Kim WJ, Yoo YH, Choi YH (2014) Beta-lapachone-induced apoptosis of human gastric carcinoma AGS cells is caspase-dependent and regulated by the PI3K/ Akt pathway. Biomol Ther (Seoul) 22(3):184-192

47. Sato A, Asano T, Isono M, Ito K, Asano T (2014) Ritonavir acts synergistically with panobinostat to enhance histone acetylation and inhibit renal cancer growth. Mol Clin Oncol 2(6): 1016-1022 